\title{
The Socioeconomic Impact of Health Research in Iranian Universities of Medical Sciences: experiences from Islamic Republic of Iran
}

\author{
Monir Baradaran Eftekhari 1 (D), Asghar Ebadifar 1, 2, 3* id , Katayoun Falahat 1 (iD
}

1. Deputy for Research and Technology, Ministry of Health and Medical Education, Tehran, Iran

2. Dentofacial Deformities Research Center, Shahid Beheshti University of Medical Sciences, Tehran, Iran

3. Dept. of Orthodontics, School of Dentistry, Shahid Beheshti University of Medical Sciences, Tehran, Iran

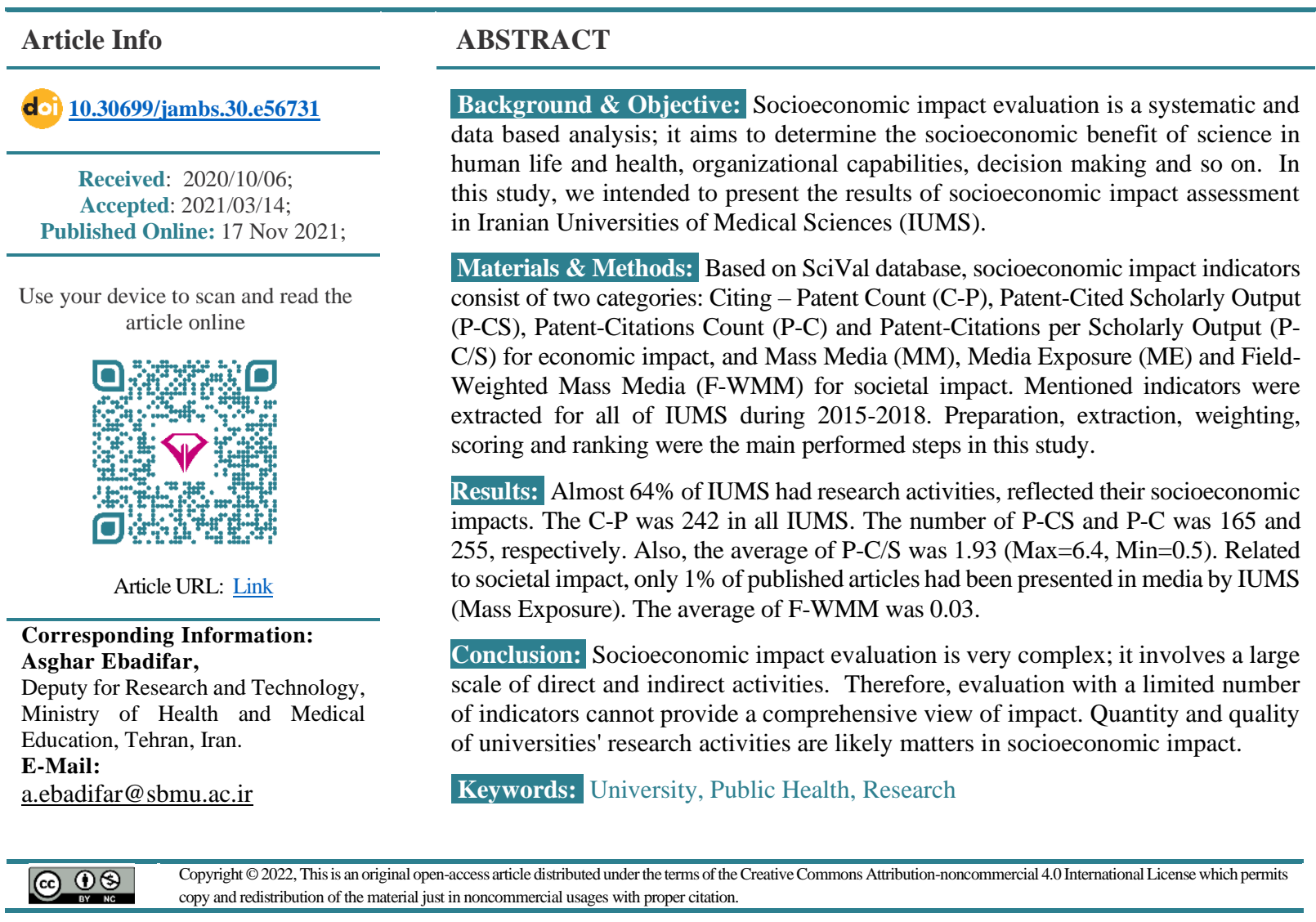

\section{Introduction}

Research impact assessment is a systematic and data based analysis, which aim to determine or predict the social or economic impacts of research and related activities (1). In fact, the scope of research evaluation has become more widespread; it does not only cover the product (output), utilization and benefits (2) but also assesses the impact of science on human life and health, organizational capabilities, group behavior, environment and so on (3).

Up to now, one of the most advanced examples of impact assessment has taken place in the Netherlands. In this country, research evaluation is carried out along with a qualitative assessment, and mainly focuses on the economic value of government funded studies (4). Also, based on the Muhonen study in 2020 in the Netherlands, a conceptual framework was developed for evaluating societal research impact. The pipeline model was also a robust tool for societal impact evaluation in other countries (5).
In 2018, Stina Hansson identified three main key aspects of effective research impact, consisting of relevancy, credibility, and legitimacy (6). In many countries, societal quality evaluation especially for basic and strategic research is not clear (5). In fact, there are knowledge gaps and challenges for sustainability assessment of societal impact (7). In many studies, the social impact of research is greater than to show (8); in almost all, different systematic measurements and related indicators are completely absent from the literature. In recent years, there is more emphasis on social impact assessment, especially in medical and health fields (9).

Economic impact analyses often estimate three types of impact, consist of Output Impact, Value Added impact and Labor Income Impact. In economic impact evaluation, measuring the return on investments is feasible, but it is not economical; it should be accurate and eligible in the rational assessment budget, which 
assesses a small percentage of the invested money in the research (10).

In order to assess the socio-economic impact, it is needed to have valid and reliable indicators. The indicators should have clearly coherence between what is measured and what should be measured (9). Also, it is especially desirable to have simple indicators, which provide a meaningful assessment (11)

Today, different institutions design research impact evaluation indicators. In the United Kingdom, Research Excellence Framework (REF) is one of the best well-known evaluation systems, which has evaluated all kinds of social, economic and cultural impacts beyond academia (12). In 2009, Elsevier has established another citation database named SciVal, which is one of the most professional scientometric tools for research organizations and universities. This database has many practical functions, such as societal and economic impact evaluation (13).

Also, In Iran, various indicators have been designed to evaluate all Iranian Universities of Medical Sciences (IUMS) and Medical Research Centers (MRCs) research activities since 2000. Many of these indicators have been used for output evaluation, and there are few indicators for impact assessment; there has never been enough attention to socio economic effect of research (14-17).

So, in this study by extracting the impact indicators values in SciVal, we evaluated the socioeconomic impact of researches in IUMS for the first time. This research is important because of two main reasons; the first, for the first time in Iran, the data based on a credible database has been used for socioeconomic evaluation, and the second, the level of evaluation has been deepened and transcends the output layer, and dealt with effectively.

\section{Materials and Methods}

\section{Property Setting}

This study was carried out in Iran. Iran has 53 Medical Sciences Universities, with almost 20000 faculty members and more non-faculty researchers.

\section{Design}

This scientometric study was implemented in 2019. The socioeconomic impact indicators of all IUMS during 2013-2018 have been extracted from SciVal (16). SciVal is designed by Elsevier Research Intelligence. It estimates research performance indicators, and works based on the Scopus database. SciVal receives patent article citations from European Patent Office, Intellectual Office, Japan Patent Office, United States Patent and Trademark Office. All the published patents data are accessible for almost eighteen months after the application date.

For societal impact evaluation, data is drawn from 45,000 sources, including 39,000 online sources and 6,000 print sources. In SciVal, economic impacts have been assessed by four indicators consist of Citing - Patent Count (C-P), Patent-Cited Scholarly Output (P-CS), Patent-Citations Count (P-C) and Patent-Citations per Scholarly Output (P-C/S). Also, there are three indicators for societal impact evaluation that include Mass Media (MM), Media Exposure (ME) and Field-Weighted Mass Media (F-WMM). Table 1 shows the socioeconomic metrics and their descriptions.

Table 1: Socio-economic indicators and their description

\begin{tabular}{|c|c|}
\hline Economic impact indicators & Description \\
\hline Citing-Patents Count & $\begin{array}{l}\text { The number of patents received by European Patent Office, Intellectual Property } \\
\text { Office, Japan Patent Office, United States Patent and Trademark Office, citing the } \\
\text { scientific output published by IUMS during 2013-2018 }\end{array}$ \\
\hline Patent-Cited Scholarly Output & $\begin{array}{l}\text { The number of scientific outputs published by IUMS indexed in Scopus database, } \\
\text { which have been cited in patents during 2013-2018 }\end{array}$ \\
\hline Patent-Citations Count & The number of patent citations received by IUMS during 2013-2018 \\
\hline Patent-Citations per Scholarly Output & $\begin{array}{l}\text { Average patent-citations received per 1,000 scientific outputs published by I } \\
\text { during } 2013-2018\end{array}$ \\
\hline Societal impact indicators & Description \\
\hline Mass Media & Number of mentions in 45000 media sources received by IUMS during 2013-2018 \\
\hline Media Exposure & $\begin{array}{l}\text { Number of mentioned media weighted by type of publication, demographics and } \\
\text { audience, which has been reached by IUMS during 2013-2018 }\end{array}$ \\
\hline Field-Weighted Mass Media & $\begin{array}{l}\text { The ratio of Mass Media relative to the expected world average for the subject } \\
\text { field, publication type and publication year. }\end{array}$ \\
\hline
\end{tabular}




\section{Study plan}

Four main steps have been considered for this study:

1- Preparation of the study samples: At this point, the list of all medical sciences universities was prepared, and then their affiliations were retrieved by searching in the Scopus database.

2- Extraction of the socioeconomic impact indicators: After registering in the SciVal database, in the overview menu, each medical university's affiliation was entered to "Add institutions and groups box" in a database; the values of socioeconomic impact indicators were extracted and recorded to excel sheet.

3- Weighting and scoring the indicators: At first, the raw value of each index was calculated. Then, based on Hundredth factor, the maximum score was estimated for the top raw. For the others, the adjusted score was calculated. Based on the research team's opinion, the weight for C-P, P-CS, $\mathrm{P}-\mathrm{C}, \mathrm{P}-\mathrm{C} / \mathrm{S}$ in economic impact was $2.5,3.5,4,2$, respectively. In societal impact, the weight of MM, ME, F-WMM was 2, 3, 4, respectively. The weighting criteria have been considered the importance and accuracy of the indicators.

There is statistical formula to estimate final scores of each indicator as follow. For example:

Max Score (top IUMS) $=$ weight of impact indicator*100\&

For others: Adjusted Score $(n)=\frac{\text { raw score }(n) * \text { Max score }}{\text { maximum raw score }}$

The raw value for MM in IUMS-x is 118, The weight of this indicator is 2 . The Max score is also $2 * 100=200$, Maximum raw score in this indicator is 320 and the Adjusted score of MM is $(118 * 2 * 100) / 320=73.75$.

In the cited example, adjusted scores for other indicators in societal impact, concluding ME and FWMM are 110.53 and 400 respectively. Finally, the

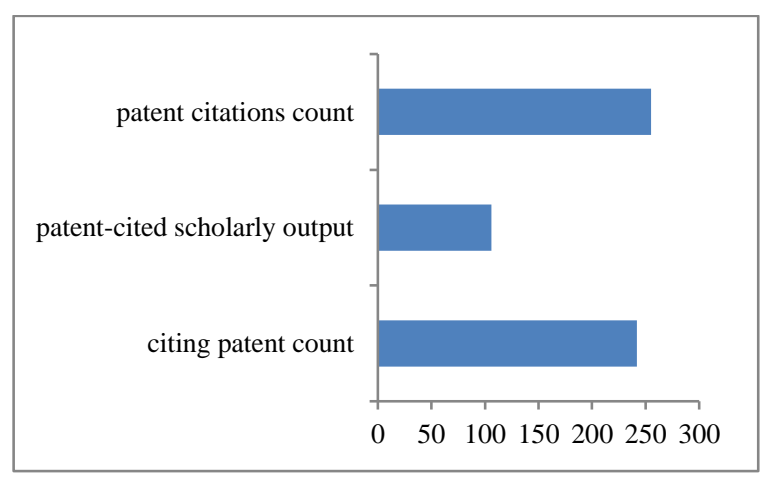

Figure 1: Economic impact indicators in IUMS societal impact score for IUMS-x will be calculated based on sum of $73,75,110,53$ and 400 .

Ranking the IUMS based on the economic and societal indicators: Sum of adjusted scores for all of the indicators determined the total score. IUMS ranking was done based on the descended total score.

For six IUMS, all the socioeconomic impact indicators were extracted as a pilot study.

Problems and challenges of the study were resolved, and the study entered its original phase.

Problems and challenges of the study were resolved, and the study entered its original phase.

In this project, all ethical aspects have been considered. All of data were analyzedbased on the descriptive statistics in SPSS software version 20.

\section{Results}

In this study, 35 IUMS had $1 \mathrm{C}-\mathrm{P}$ at least. It means, that 18 IUMS did not have any economic impact score. The C-P was 242 in all of IUMS during 2013-2018. The number of P-CS and P-C was 165 and 255, respectively. Also, the average of P-C/S was 1.93 ( $\max =6.4, \mathrm{Min}=0.5)$. Figure 1 shows IUMS economic impact indicators.

The three tops IUMS in the economic impact score were Tehran, Shahid Beheshti and Tabriz; Almost half of C-P $(46.6 \%)$ in Iran is affiliated with these.

Related to societal impact, only in 34 cases, there were one or more mentions in the media received by IUMS. The total number of published articles indexed in Scopus by IUMS was 86150 during 2013-2018, and the total number of mentions in the media was 952. In other words, almost every two days, the media received a mention regarding IUMS research activities. The average of F-WMM was 0.03 . The three top scores in societal impact were related to Tehran, Mashhad and Shiraz university of medical sciences (Table 2 and 3). Figure 2 shows the percentage of published articles, which were mentioned in the media.

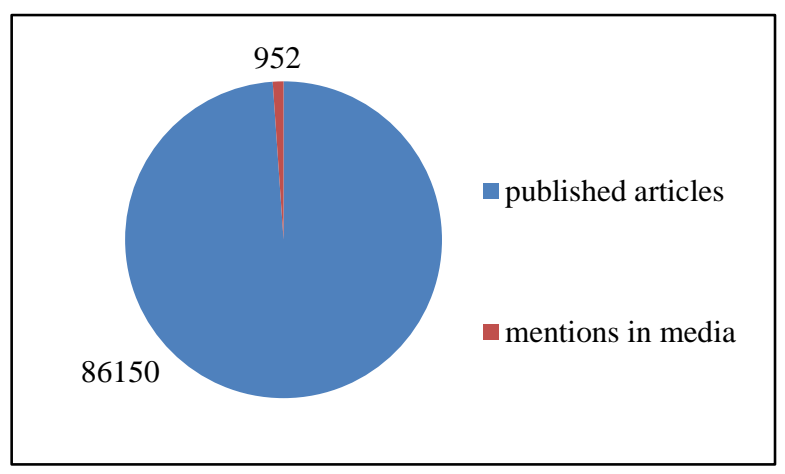

Figure 2: Total number of published articles by IUMS, which mentioned in the media during 20132018 


\section{Table 2: Economic Impact Score in IUMSs}

\begin{tabular}{|c|c|c|c|c|c|c|}
\hline IUMS & $\begin{array}{l}\text { Citing-Patents } \\
\text { count }\end{array}$ & $\begin{array}{l}\text { Patent-Cited } \\
\text { Scholarly } \\
\text { Output }\end{array}$ & $\begin{array}{l}\text { Patent- } \\
\text { Citations } \\
\text { Count }\end{array}$ & $\begin{array}{c}\text { Patent-Citations } \\
\text { per Scholarly } \\
\text { Output }\end{array}$ & $\begin{array}{c}\text { Economic } \\
\text { Impact Score }\end{array}$ & Rank \\
\hline Tehran & $47(250)$ & $39(350)$ & $50(400)$ & $1.90(59.38)$ & 1059.38 & 1 \\
\hline Shahid Beheshti & $42(223)$ & 20(179) & $46(368)$ & $3.20(100)$ & 870.89 & 2 \\
\hline Tabriz & $24(128)$ & $17(153)$ & $26(208)$ & $3.50(109.38)$ & 597.6 & 3 \\
\hline Shiraz & $25(133)$ & 13(117) & $25(200)$ & $3.30(103.13)$ & 552.77 & 4 \\
\hline Iran Pasteur Ins & $12(64)$ & $9(81)$ & $16(128)$ & $6.40(200)$ & 472.6 & 5 \\
\hline Mashhad & $18(96)$ & $14(126)$ & $18(144)$ & $2.20(68.75)$ & 434.14 & 6 \\
\hline Isfahan & $17(90)$ & $12(108)$ & 17(136) & $2.2(68.75)$ & 402.87 & 7 \\
\hline Urmia & $5(27)$ & $2(18)$ & $5(40)$ & $3.8(118.75)$ & 203.29 & 8 \\
\hline Mazandaran & $7(37)$ & $2(18)$ & $7(56)$ & $2.1(65.63)$ & 176.81 & 9 \\
\hline Kermanshah & $5(27)$ & $4(36)$ & $5(40)$ & $1.5(46.88)$ & 149.37 & 10 \\
\hline Lorestan & $3(16)$ & $2(18)$ & $3(24)$ & $2.6(81.25)$ & 139.16 & 11 \\
\hline Bushehr & $2(11)$ & $2(18)$ & $2(16)$ & $3(78.13)$ & 122.71 & 12 \\
\hline Kashan & $3(16)$ & $1(9)$ & $3(24)$ & $2.3(71.88)$ & 120.81 & 13 \\
\hline Babol & $3(16)$ & $3(27)$ & $3(24)$ & $1.7(53.13)$ & 120.01 & 14 \\
\hline Ardabil & $2(11)$ & $1(9)$ & $2(16)$ & $2.7(84.38)$ & 119.99 & 15 \\
\hline Jahrom & $1(5)$ & $1(9)$ & $1(8)$ & $2.3(71.88)$ & 94.17 & 16 \\
\hline Fasa & $1(5)$ & $1(9)$ & $1(8)$ & $2.3(71.88)$ & 94.17 & 17 \\
\hline Arak & $2(11)$ & $1(9)$ & $2(16)$ & $1.8(56.25)$ & 91.86 & 18 \\
\hline North Khorasan & $1(5)$ & $1(9)$ & $1(8)$ & $2(68.75)$ & 91.04 & 19 \\
\hline Kurdistan & $2(11)$ & $2(18)$ & $2(16)$ & $1.4(43.75)$ & 88.34 & 20 \\
\hline Baqiyatallah & $3(16)$ & $2(18)$ & $3(24)$ & $0.8(25)$ & 82.91 & 21 \\
\hline Zahedan & $2(11)$ & $1(9)$ & $2(16)$ & $1.2(37.5)$ & 73.11 & 22 \\
\hline Yazd & $2(11)$ & $2(18)$ & $2(16)$ & $0.9(28.13)$ & 72.71 & 23 \\
\hline Yasouj & $1(5)$ & 1(9) & $1(8)$ & $1.6(50)$ & 72.29 & 24 \\
\hline Ahwaz & $2(11)$ & $2(18)$ & $2(16)$ & $0.5(15.63)$ & 60.21 & 25 \\
\hline Zabol & $1(5)$ & $1(9)$ & $1(8)$ & $1.20(37.5)$ & 59.79 & 26 \\
\hline Qazvin & $1(5)$ & $1(9)$ & $1(8)$ & $0.90(28.13)$ & 50.42 & 27 \\
\hline Ilam & $1(5)$ & $1(9)$ & $1(8)$ & $0.90(28.13)$ & 50.42 & 27 \\
\hline Zanjan & $1(5)$ & $1(9)$ & $1(8)$ & $0.80(25)$ & 47.29 & 28 \\
\hline Alborz & $1(5)$ & $1(9)$ & $1(8)$ & $0.80(25)$ & 47.29 & 28 \\
\hline Guilan & $1(5)$ & $1(9)$ & $1(8)$ & $0.70(21.88)$ & 44.17 & 29 \\
\hline Shahrekord & $1(5)$ & $1(9)$ & $1(8)$ & $0.60(18.75)$ & 41.04 & 30 \\
\hline $\begin{array}{c}\text { University of Social } \\
\text { welfare }\end{array}$ & $1(5)$ & $1(9)$ & $1(8)$ & $0.50(15.63)$ & 37.92 & 31 \\
\hline Kerman & $1(5)$ & $1(9)$ & $1(8)$ & $0.30(9.38)$ & 31.67 & 32 \\
\hline Iran & $1(5)$ & $1(9)$ & $1(8)$ & $0.10(3.13)$ & 25.42 & 33 \\
\hline
\end{tabular}


Table 3: Societal Impact Score in IUMS

\begin{tabular}{|c|c|c|c|c|c|}
\hline IUMS & Mass Media & Media Exposure & $\begin{array}{l}\text { Field-Weighted } \\
\text { Mass Media }\end{array}$ & $\begin{array}{l}\text { Societal Impact } \\
\text { Score }\end{array}$ & Rank \\
\hline Tehran & $320(200)$ & $98.8(300)$ & $0.12(400)$ & 900 & 1 \\
\hline Mashhad & $118(73.75)$ & $36.4(110.53)$ & $0.12(400)$ & 584.28 & 2 \\
\hline Shiraz & $122(76.25)$ & $36.6(111.13)$ & $0.10(333.33)$ & 520.72 & 3 \\
\hline Isfahan & 149(93.12) & $44.9(136.34)$ & $0.08(266.67)$ & 496.13 & 4 \\
\hline ShahidBeheshti & $140(87.5)$ & $42.6(129.35)$ & $0.07(233.33)$ & 450.19 & 5 \\
\hline Hormozgan & $18(11.25)$ & $5.4(16.4)$ & $0.1(333.33)$ & 360.98 & 6 \\
\hline Qazvin & $36(22.5)$ & $10.8(32.79)$ & $0.08(266.67)$ & 321.96 & 7 \\
\hline Iran Pasteur Ins & $22(13.75)$ & $6.6(20.04)$ & $0.08(266.67)$ & 300.46 & 8 \\
\hline Babol & $4(2.5)$ & $1.2(3.64)$ & $0.07(233.33)$ & 239.48 & 9 \\
\hline Tabriz & $33(20.62)$ & $9.9(30.06)$ & $0.05(166.67)$ & 217.35 & 10 \\
\hline $\begin{array}{l}\text { University of Social } \\
\text { welfare }\end{array}$ & $13(8.12)$ & $4.1(12.45)$ & $0.05(166.67)$ & 187.24 & 11 \\
\hline Ilam & $7(4.3)$ & $2.1(6.38)$ & $0.05(166.67)$ & 177.42 & 12 \\
\hline Yazd & $6(3.7)$ & $1.80(5.47)$ & $0.05(166.67)$ & 175.88 & 13 \\
\hline Gonabad & $5(3.12)$ & $1.50(4.55)$ & $0.05(166.67)$ & 174.35 & 14 \\
\hline Kerman & $9(5.62)$ & $2.90(8.81)$ & $0.04(133.33)$ & 147.76 & 15 \\
\hline Urmia & $9(5.62)$ & $2.70(8.2)$ & $0.04(133.33)$ & 147.16 & 16 \\
\hline Ahwaz & $10(6.25)$ & $3.00(9.11)$ & $0.03(100)$ & 115.36 & 17 \\
\hline Guilan & $6(3.75)$ & $1.80(5.47)$ & $0.03(100)$ & 109.22 & 18 \\
\hline Semnan & $4(2.5)$ & $1.20(3.64)$ & $0.03(100)$ & 106.14 & 19 \\
\hline Iran & $24(15)$ & $7.70(23.38)$ & $0.02(66.67)$ & 105.05 & 20 \\
\hline Ardabil & $3(1.8)$ & $0.90(2.73)$ & $0.03(100)$ & 104.61 & 21 \\
\hline Zahedan & $5(3.1)$ & $1.50(4.55)$ & $0.02(66.67)$ & 74.35 & 22 \\
\hline Baqiyatallah & $5(3.1)$ & $1.40(4.25)$ & $0.02(66.67)$ & 74.04 & 23 \\
\hline Birjand & $2(1.25)$ & $0.6(1.82)$ & $0.02(66.67)$ & 69.74 & 24 \\
\hline Alborz & $1(0.62)$ & $0.3(0.91)$ & $0.02(66.67)$ & 68.2 & 25 \\
\hline Mazandaran & $10(6.25)$ & $2.9(8.81)$ & $0.01(33.33)$ & 48.39 & 26 \\
\hline Kermanshah & $4(2.5)$ & $1(3.04)$ & $0.01(33.33)$ & 38.87 & 27 \\
\hline Bushehr & $1(0.62)$ & $0.3(0.91)$ & $0.01(33.33)$ & 34.87 & 27 \\
\hline Zanjan & $1(0.62)$ & $0.3(0.91)$ & $0.01(33.33)$ & 34.87 & 27 \\
\hline Qom & $1(0.62)$ & $0.3(0.91)$ & $0.01(33.33)$ & 34.87 & 27 \\
\hline Kurdistan & $1(0.62)$ & $0.3(0.91)$ & $0.01(33.33)$ & 34.87 & 27 \\
\hline Golestan & $1(0.62)$ & $0.3(0.91)$ & $0.01(33.33)$ & 34.87 & 27 \\
\hline Lorestan & $1(0.62)$ & $0.3(0.91)$ & $0.01(33.33)$ & 34.87 & 27 \\
\hline Arak & $1(0.62)$ & $0.2(0.61)$ & $0.01(33.33)$ & 34.57 & 28 \\
\hline
\end{tabular}




\section{Discussion}

Based on our study results, more than one-third of the IUMS had no health research activities with socioeconomic impact, and the index values for almost one-third of the IUMS were at the minimum level.

The maximum values of indicators affiliated to Tehran University of medical sciences. In this university, the C-P count was only 47 . In the Turkey universities such as Ankara University or Istanbul University, this index value is 1 and 17, respectively. This index value for Harvard, Stanford and California universities is 1553, 727 and 2609, respectively (16). Based on Valero et al. study in 2019, the size and quality of research activities in universities are likely to matter in economic impact. Also, patents registration has a positive direct association with GDP per Capita or economic effects. In a region or country, $10 \%$ increase in the number of universities is associated with an almost $0.4 \%$ higher GDP per capita (17).

Research impact assessment in many studies has been done according to citation based indicators, reducing cost or working days lost due to illness and so on. Yazdizadeh et al. studied the impact assessment of 238 Iranian research projects, according to the payback framework. They found that, only $5.3 \%$ of research projects have been used by the Iranian Ministry of Health and Medical Education in policymaking; of which, $62 \%$ were expected to lead to health impacts directly, and nearly $36 \%$ had potentially economic impact, such as reducing cost or number of working days lost due to illness (18).

It should also be noted, that entrepreneurship such as establishment of knowledge-based corporations is very effective to enhance the economic impact. In the United Kingdom, entrepreneurial spin-offs in high economic impact universities and knowledge translation exchange in others are associated with higher economic impact (19).

Regarding to societal impact, since this phenomenon is very complex and involves a large scale of direct and indirect activities, it will be hard to develop objective and simple indicators. Mass media or media exposure are two indicators to measure societal impact of research by knowledge translation to the community (20).

Based on our results, almost $64 \%$ of IUMS had research activities with societal impacts. The maximum MM $(\max =320)$ was related to Tehran university of medical sciences. Harvard, Stanford and California MM index was 51405, 27215 and 91951, respectively (18). In 2007, Martin described four problems in societal impact assessments, consist of causality, attribution, internationality and evaluation timescale problems (21).

This study has some strengths and weak points. One of the most important strengths is using simple and accessible indicators based on the scientific reliable database. Also, establishing a valuable scoring system based on stakeholders opinions is associated with complet innovation. The most important weak point in this study is failure to consider all aspects of economic and social in research.

\section{Conclusion}

Socioeconomic impact evaluation is very complex, and involves a large scale of direct and indirect activities. Therefore, evaluation by a limited number of indicators cannot provide a comprehensive view of the effect. Quantity and quality of research activities in universities are likely to matter in socioeconomic impact.

\section{Acknowledgment}

The authors wish to thank the Research Experts at the Deputy of Research and Technology - Ministry of Health and Medical Education and universities of medical science for their assistance with data collection and review.

\section{Conflicts of Interest}

There is no conflict of interest.

\section{References}

1. Schoenefeld J, Jordan A. Governing policy evaluation? Towards a new typology. Evaluation. 2017;23(3):274-93. [DOI:10.1177/1356389017715366]

2. Rau H, Goggins G, Fahy F. From invisibility to impact: Recognising the scientific and societal relevance of interdisciplinary sustainability research. Res Policy. 2018;47(1):266-76. [DOI:10.1016/j.respol.2017.11.005]

3. Rawhouser H, Cummings M, Newbert SL. Social impact measurement: Current approaches and future directions for social entrepreneurship research. $\quad$ ETP. 2019;43(1):82-115. [DOI:10.1177/1042258717727718]

4. Donovan C. The Australian Research Quality Framework: A live experiment in capturing the social, economic, environmental, and cultural returns of publicly funded research. New Dir Eval. 2008;(118):47-60. [DOI:10.1002/ev.260]

5. Muhonen R, Benneworth $\mathrm{P}$, Olmos-Peñuela $\mathrm{J}$. From productive interactions to impact pathways: Understanding the key dimensions in developing SSH research societal impact. Res Eval. 2020;29(1):34-47. [DOI:10.1093/reseval/rvz003]

6. Hansson S, Polk M. Assessing the impact of transdisciplinary research: The usefulness of relevance, credibility, and legitimacy for understanding the link between process and impact. Res Eval. 2018;27(2):132-44. [DOI:10.1093/reseval/rvy004] 
7. Mancini L, Sala S. Social impact assessment in the mining sector: Review and comparison of indicators frameworks. Resources Policy. 2018;57:98-111.

[DOI:10.1016/j.resourpol.2018.02.002]

8. Niederkrotenthaler $\mathrm{T}$, Dorner TE, Maier $\mathrm{M}$. Development of a practical tool to measure the impact of publications on the society based on focus group discussions with scientists. BMC Public Health. 2011;11(1):1-9. [DOI:10.1186/1471-2458-11-588]

9. Reale E, Avramov D, Canhial K, et al. A review of literature on evaluating the scientific, social and political impact of social sciences and humanities research. Res Eval. 2018;27(4):298-308. [DOI:10.1093/reseval/rvx025]

10. Brazier J, Ratcliffe J, Saloman J, Tsuchiya A. Measuring and valuing health benefits for economic evaluation.2nd ed. United Kingdom: OXFORD university press; 2017. [DOI:10.1093/med/9780198725923.001.0001]

11. Molas-Gallart J, Salter A, Patel P, Scott A, Duran $X$. Measuring third stream activities. Final report to the Russell Group of Universities. Brighton: SPRU, University of Sussex. 2002.

12. Ernø-Kjølhede E, Hansson F. Measuring research performance during a changing relationship between science and society. Res Eval. 2011;20(2):131-43. [DOI:10.3152/095820211X12941371876544]

13. Djalalinia S, Owlia P, Forouzan AS, et al. Health research evaluation and its role on knowledge production. Iran J public health. 2012;41(2):39.
14. Djalalinia S, Peykari N, Owlia P, et al. The analysis of health research system evaluation in medical sciences universities. Iran J Public Helath. 2013;42(Supple1):60.

15. Peykari N, Djalalinia S, Owlia P, et al. Health research system evaluation in IR of Iran. Arch Iran Med. 2012;15(7):0-.

16. Elsevier Research Intelligence, The societal impact indicators. Available from: https://www.scival.com/overview/societalImpact? uri=Institution/404024. [Accessed 10 May 2020].

17. Valero A, Van Reenen J. The economic impact of universities: Evidence from across the globe. Econ Educ Rev. 2019;68:53-67. [DOI:10.1016/j.econedurev.2018.09.001]

18. Yazdizadeh B, Majdzadeh R, Janani L, et al. An assessment of health research impact in Iran. Health Res Policy Syst. 2016;14(1):1-10. [DOI:10.1186/s12961-016-0129-9]

19. Guerrero M, Cunningham JA, Urbano D. Economic impact of entrepreneurial universities' activities: An exploratory study of the United Kingdom. Res Policy. 2015;44(3):748-64. [DOI:10.1016/i.respol.2014.10.008]

20. Gregersen B, Linde LT, Rasmussen JG. Linking between Danish universities and society. Science and public policy. 2009;36(2):151-6. [DOI:10.3152/030234209X406818]

21. Martin BR, editor Assessing the impact of basic research on society and the economy. Rethinking the impact of basic research on society and the economy (WF-EST International Conference, 11 May 2007), Vienna, Austria; 2007.

\section{How to Cite This Article:}

